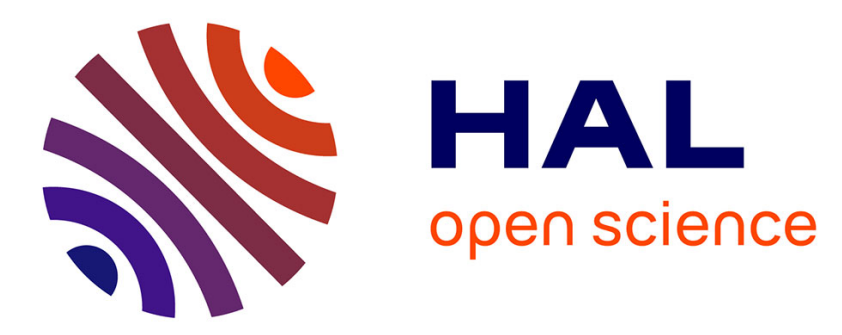

\title{
Soft projectile impacts analysis on thin reinforced concrete slabs: Tests, modelling and simulations
}

\author{
C. Pontiroli, A. Rouquand, Laurent Daudeville, J. Baroth
}

\section{To cite this version:}

C. Pontiroli, A. Rouquand, Laurent Daudeville, J. Baroth. Soft projectile impacts analysis on thin reinforced concrete slabs: Tests, modelling and simulations. European Journal of Environmental and Civil Engineering, 2012, Vulnerability of constructions under impacts and explosions, 16 (9), pp.10581073. 10.1080/19648189.2012.699745 . hal-02002420

\section{HAL Id: hal-02002420 \\ https://hal.univ-grenoble-alpes.fr/hal-02002420}

Submitted on 14 Sep 2020

HAL is a multi-disciplinary open access archive for the deposit and dissemination of scientific research documents, whether they are published or not. The documents may come from teaching and research institutions in France or abroad, or from public or private research centers.
L'archive ouverte pluridisciplinaire HAL, est destinée au dépôt et à la diffusion de documents scientifiques de niveau recherche, publiés ou non, émanant des établissements d'enseignement et de recherche français ou étrangers, des laboratoires publics ou privés. 


\title{
Soft projectile impacts analysis on thin reinforced concrete slabs: Tests, modelling and simulations
}

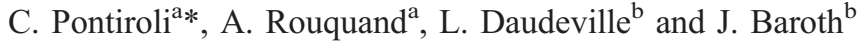 \\ ${ }^{a}$ Comissariat à l'Energie Atomique, Centre de Gramat (CEA-Gramat), Gramat, France; \\ ${ }^{b}$ Université Joseph Fourier - Grenoble 1/Grenoble INP/CNRS, 3SR Lab, Grenoble, France
}

\begin{abstract}
Numerical simulations of reinforced concrete structures subjected to high velocity impacts and explosions remain a difficult task today. For 10 years and more now, the CEA-Gramat has maintained a continuous research effort with the help of different French universities in order to overcome encountered difficulties in modelling the behaviour of concrete structures under severe loading. To get more data on aircraft impact problems and then validate numerical models, soft projectile impacts tests at small scale on thin reinforced concrete slabs has been carried out at CEAGramat. Numerical simulations of these tests have been carried out and compared with experimental results to validate our numerical approach.
\end{abstract}

La simulation numérique de structures en béton armé soumises à des impacts à grande vitesse et à de fortes explosions reste encore aujourd'hui une tâche difficile. Depuis plus de dix ans, le CEA-Gramat poursuit un programme de recherche, avec la participation de plusieurs laboratoires universitaires français, afin de lever les difficultés associées à la modélisation du comportement des structures en béton sous chargement extrême. Pour acquérir des données sur la tenue de structures aux impacts d'avions et ainsi pouvoir valider les outils numériques qu'il développe, le CEA-Gramat a réalisé un certain nombre de tests expérimentaux d'impacts de projectiles déformables sur des dalles en béton armé peu épaisses. Les simulations numériques de ces essais ont été réalisées et comparées aux résultats expérimentaux afin de valider les outils numériques mis en place au CEA-Gramat.

Keywords: impact; experiment; concrete model; simulation

Mots-clés: impact; experimentations; modèle de comportement; béton; simulation

\section{Introduction}

Reinforced concrete structures like nuclear plants have to withstand the impact of different types of projectiles. A lot of experimental work has been carried out for military threats in the past to investigate the effect of rigid projectile impacts, but few results are available on the interaction between a concrete structure and a highly deformable projectile (Riech \& Rüdiger, 1984).

Recently, CEA-Gramat has participated in the International benchmark called IRIS 2010. This benchmark was co-organised by the French Institute of Radio Protection and Nuclear Safety (IRSN) and by the VTT Research Institute in Finland. Some results of this test were known and the participants could use these experimental data to optimise their numerical results (Riech \& Rüdiger, 1984). Others tests were performed by

*Corresponding author. Email addresses: christophe.pontiroli@cea.fr; jbaroth@ujf-grenoble.fr 
the VTT research centre and the results were unknown (Saarenheimo, Tuomala, Hakola, Hyvärinen, Aalto, \& Myllymäki, 2007). The numerical simulations of these tests were blind simulations. Good results were on the whole obtained with CEA-Gramat on these simulations (Rouquand, 2010), but some data like material characteristics were insufficient and some assumptions have been made while performing the simulations.

In the framework of the French VULCAIN PGCU 2007 research project (founded by the French National Research Agency), CEA-Gramat has proposed to carry out impact tests on reinforced concrete slabs with deformable projectiles. Concrete and steel material used for slabs have been characterised to give material parameters to numerical models, and a specific experiment has been developed to characterise the projectile crushing.

Soft impact induces both local damage and overall global dynamic response of the target. As shown in Figure 1 (Jonas, Rüdiger, Gries, Riech, \& Rûtzel, 1982) local damage consists of several processes: In a first stage (Figure 1(1) to (4)), the projectile crushes and creates cratering on the front face of the reinforced concrete slab. Some shear cracks are developed through the slab thickness and along the rear face reinforcement. In a second stage (Figure 1(5) to (8)), these cracks propagate and then a plugging followed by a back face scabbing damage mode appeared. If the projectile continues to push the plug, the rear reinforcements fail and the plug is completely sheared off: perforation is reached.

In this paper, new soft impact experiments are presented and the test results are compared with numerical simulations using the finite element method and a specific concrete material model.
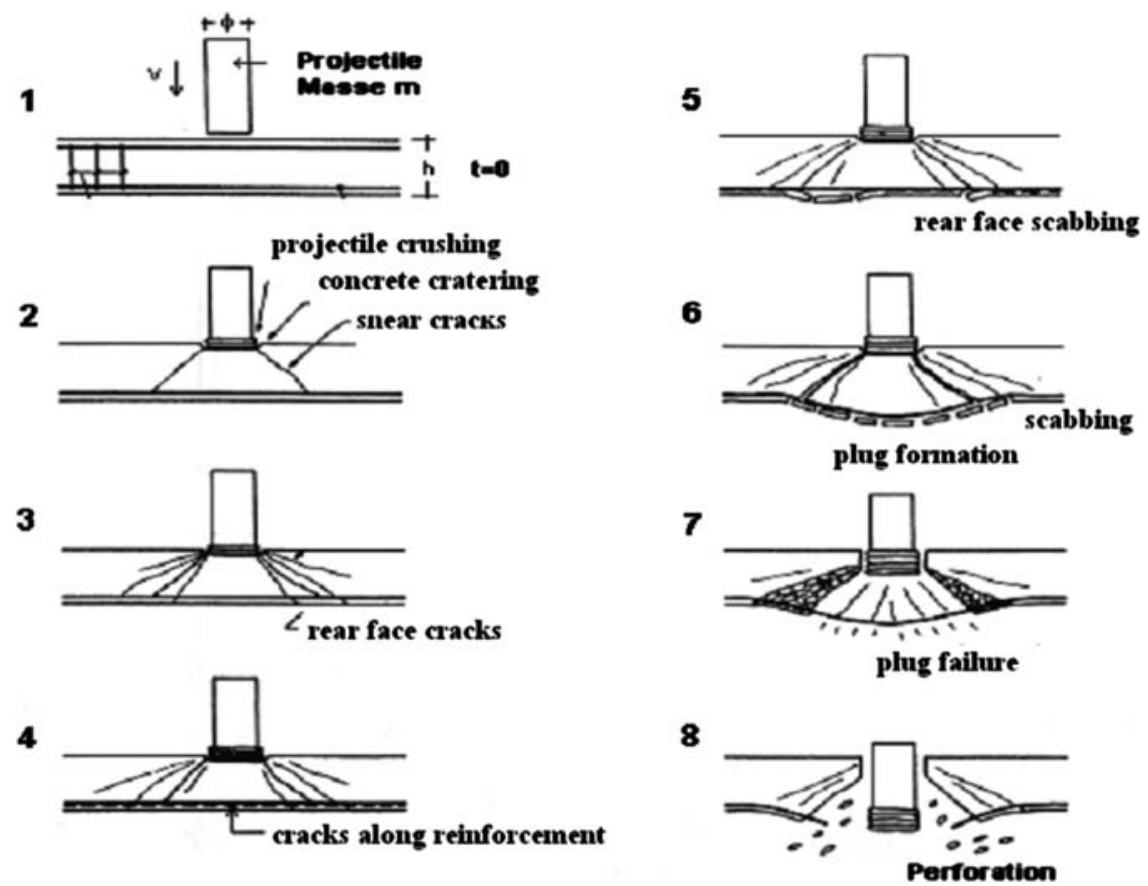

Figure 1. Successive steps of the process of soft impact on reinforced concrete slab (Jonas et al., 1982). 


\section{Impact tests}

\subsection{Experimental procedures}

A steel cylindrical projectile with sections of different thicknesses is launched at a target by a $90 \mathrm{~mm}$ calibre gas gun (Figure 2). The front part of the projectile is composed of a thin steel S235 tube $(\mathrm{D}=80 \mathrm{~mm}, \mathrm{~L}=500 \mathrm{~mm})$. This tube has a thickness of $1 \mathrm{~mm}$ over the first $250 \mathrm{~mm}$ front part and a thickness of $2 \mathrm{~mm}$ on the remaining $250 \mathrm{~mm}$ part. The third and rear part of the projectile is composed of a massive steel 35NCD16 cylinder incorporating an acceleration recorder system designed to measure the axial accelerations during the tests.

Rectangular $2 \mathrm{~m}$ by $1.2 \mathrm{~m}$ reinforced concrete slabs with a thickness of 7 or $6 \mathrm{~cm}$ have been used to simulate soft projectile impact. The projectile velocity is changed in order to get different damage levels ranging from slight bending to projectile perforation.

The target is held tight by a metallic support which is supposed to be perfectly rigid. Video cameras and displacement sensors located on the rear face of the reinforced concrete slab complete the measurements. Nine tests have been performed with different impact velocities going from 70 to $135 \mathrm{~m} / \mathrm{s}$. In this paper we present two experimental results obtained on concrete slabs of $7 \mathrm{~cm}$ thick for velocities of $107.5 \mathrm{~m} / \mathrm{s}$ (test no. 1) and $70.2 \mathrm{~m} / \mathrm{s}$ (test no. 2). Other results are gathered in Baroth, Daudeville, \& Malécot (2011).

A complementary particular test has been designed to get information on the projectile crushing behaviour. This experiment is a ballistic pendulum test which consists of measuring the projectile momentum, from which it is possible to calculate the velocity and the kinetic energy.

\subsection{Concrete composition}

A standard concrete mixture named R30A7, defined several years ago by CEA-Gramat and 3SR Laboratory at Grenoble, is used with an amount of 1.0 vol.\% steel reinforcement $(\mathrm{D}=6 \mathrm{~mm} \mathrm{~S} 235$ steel rebar with $80 \times 80 \mathrm{~mm}$ square grid, rebar are located at $19 \mathrm{~mm}$ to the faces).

The tested R30A7 concrete displays a 28-day compressive strength of about $30 \mathrm{MPa}$ and a slump of $7 \mathrm{~cm}$. It should be noted that a very high-quality cement is used. This high quality gives better material reproducibility and leads to a particularly low cement volume. Aggregate compounds, with a maximum size of $8 \mathrm{~mm}$ are obtained from natural deposits (rolled aggregates, 99\% quartzite). Table 1 gives the composition and the mechanical properties of the R30A7 concrete.
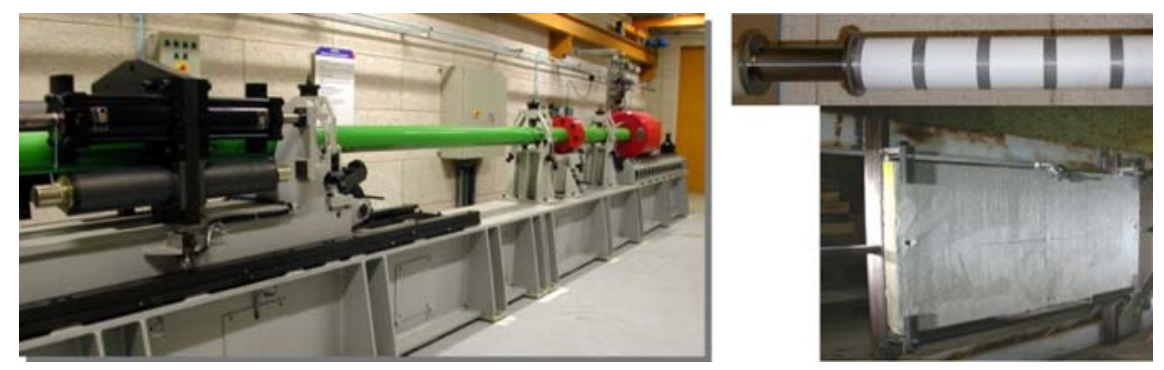

Figure 2. Gas launcher, deformable projectile and target. 
Table 1. Composition and mechanical properties of the R30A7 concrete.

\begin{tabular}{lc} 
Concrete composition & $\mathrm{R} 30 \mathrm{~A} 7$ \\
\hline $0.5 / 8$ "D" gravel $\left(\mathrm{kg} / \mathrm{m}^{3}\right)$ & 1008 \\
$1.800 \mu \mathrm{m}$ " $\mathrm{D}$ " sand $\left(\mathrm{kg} / \mathrm{m}^{3}\right)$ & 838 \\
$\mathrm{CEM}$ I $52.5 \mathrm{~N}$ PM ES CP2 cement (Vicat) $\left(\mathrm{kg} / \mathrm{m}^{3}\right)$ & 263 \\
Water $\left(\mathrm{kg} / \mathrm{m}^{3}\right)$ & 169 \\
W/C ratio & 0.64 \\
Cement paste volume Vp $\left(\mathrm{m}^{3} / \mathrm{m}^{3}\right)$ & 0.252 \\
Density $\left(\mathrm{kg} / \mathrm{m}^{3}\right)$ & 2278 \\
Mechanical properties & \\
Average tested strength in uni-axial compression at 28 days $(\mathrm{MPa})$ & 32.5 \\
Average slump measured using the Abrams cone $(\mathrm{cm})$ & 6.9 \\
Volume of occluded air measured in fresh concrete $\left(1 / \mathrm{m}^{3}\right)$ & 34 \\
Porosity accessible to water $(\%)$ & 12 \\
\hline
\end{tabular}

\subsection{Test results}

\subsubsection{Perforation test}

Test no. 1, corresponding to an initial projectile velocity of $107.5 \mathrm{~m} / \mathrm{s}$, results in perforation of the reinforced concrete slab with a projectile residual velocity of about $46.6 \mathrm{~m} / \mathrm{s}$. A series of plies are formed on the steel tube during the projectile crushing process and the first cylinder part with a thin wall thickness of $1 \mathrm{~mm}$ is completely buckled (Figure 3).

Figure 4 shows the residual damage obtained on the front and on the rear faces of the reinforced concrete target. We can observe the formation of a plugging cone on the front face with an important scabbing effect on the rear face. Several rebars fail on the rear face.

\subsubsection{Non-perforating test}

Test no. 2 presented here (initial velocity of $70.2 \mathrm{~m} / \mathrm{s}$ ), results in a rebound of the projectile. A series of plies are formed on the steel tube during the projectile crushing process and the first cylinder part with a thin wall thickness of $1 \mathrm{~mm}$ is buckled over a length of $150 \mathrm{~mm}$ (Figure 5).

Figure 6 shows the damage obtained on the front and on the rear faces of the reinforced concrete target. We can observe scabbing effects and the formation of a plugging cone, but the failure of steel reinforcement is not reached. Kinetic energy of the projectile is not sufficient to perforate the reinforced concrete slab.
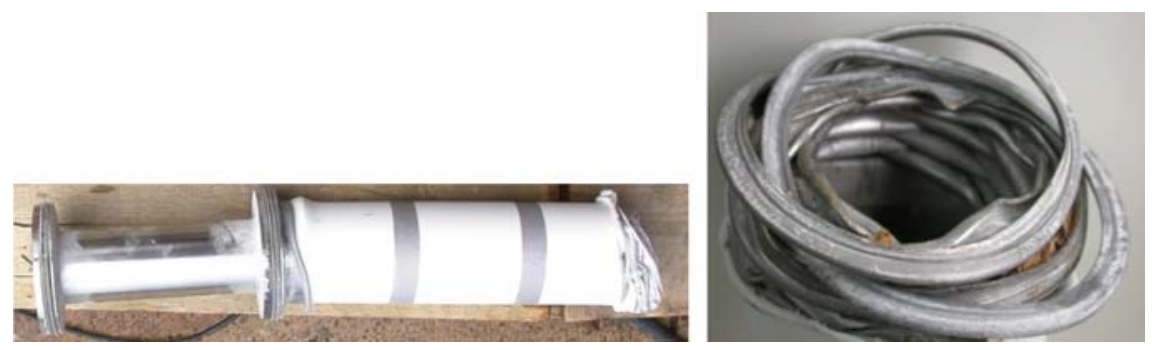

Figure 3. Deformation of the missile after perforation (test no. $1, \mathrm{~V}_{0}=107.5 \mathrm{~m} / \mathrm{s}$ ). 


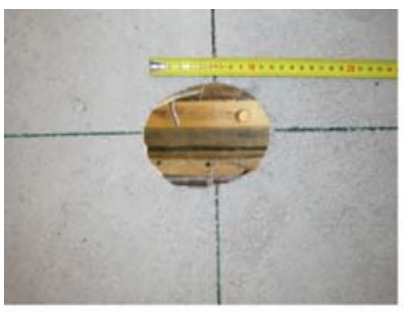

Front face

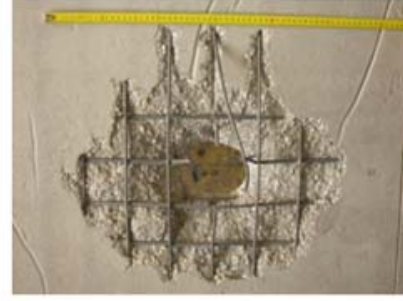

Rear face

Figure 4. Damage of the reinforced concrete slab after test no. $1\left(\mathrm{~V}_{0}=107.5 \mathrm{~m} / \mathrm{s}\right)$.
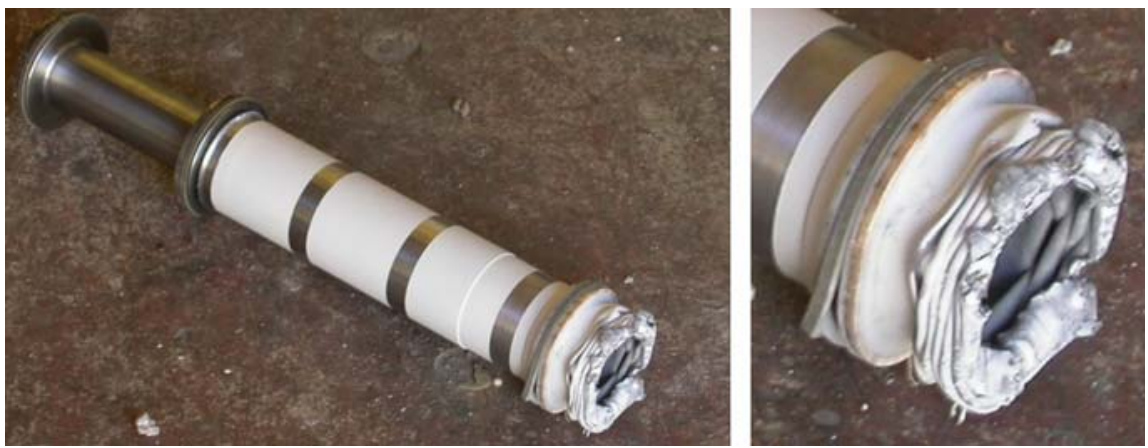

Figure 5. Deformation of the missile after perforation (test no. $2, \mathrm{~V}_{0}=70.2 \mathrm{~m} / \mathrm{s}$ ).

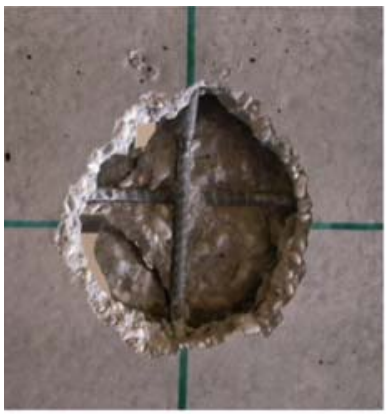

Front face

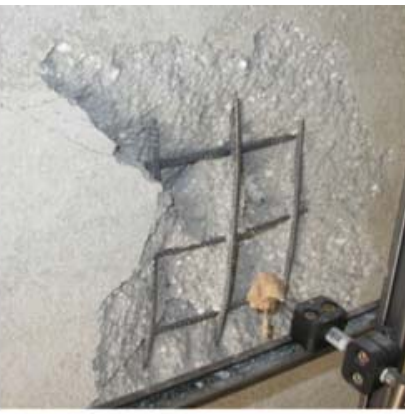

Rear face

Figure 6. Damage on the reinforced concrete slab after test no. $2, \mathrm{~V}_{0}=70.2 \mathrm{~m} / \mathrm{s}$.

\subsubsection{Ballistic limit}

Eight experimental tests have been performed on slabs with a thickness of $7 \mathrm{~cm}$ (see Table 2). As the projectiles do not have exactly the same mass, we give on Figure 7 the ballistic limit curve in terms of kinetic energy. Tests no. 1 (\#24) and no. 2 (\#32) are located on both sides of the ballistic limit which can be estimated around $92 \mathrm{~m} / \mathrm{s}$.

\subsubsection{Ballistic pendulum test}

Numerical simulations of soft projectile impact on a reinforced concrete structure require a relevant concrete model but also a good modelling of the projectile crushing 
Table 2. Specific data concerning each of eight Vulcain tests (Baroth, 2011).

\begin{tabular}{lrrrrrrrr}
\hline Reference & \multicolumn{1}{c}{ \#22 } & \multicolumn{1}{c}{ \#24 } & \multicolumn{1}{c}{$\# 30$} & \multicolumn{1}{c}{$\# 35$} & \multicolumn{1}{c}{ \#27 } & \multicolumn{1}{c}{ \#43 } & \multicolumn{1}{c}{ \#32 } & \multicolumn{1}{c}{ \#34 } \\
\hline $\mathrm{M}(\mathrm{kg})$ & 6.166 & 5.207 & 5.091 & 5.059 & 4.985 & 5.050 & 5.065 & 5.059 \\
$\mathrm{E}_{\mathrm{c}}(\mathrm{kJ})$ & 56.600 & 29.800 & 21.500 & 13.500 & 21.600 & 16.200 & 12.400 & 11.700 \\
$\mathrm{~V}(\mathrm{~m} / \mathrm{s})$ & 135.500 & 107.500 & 92.000 & 73.000 & 93.000 & 80.000 & 70.200 & 68.000 \\
\hline
\end{tabular}

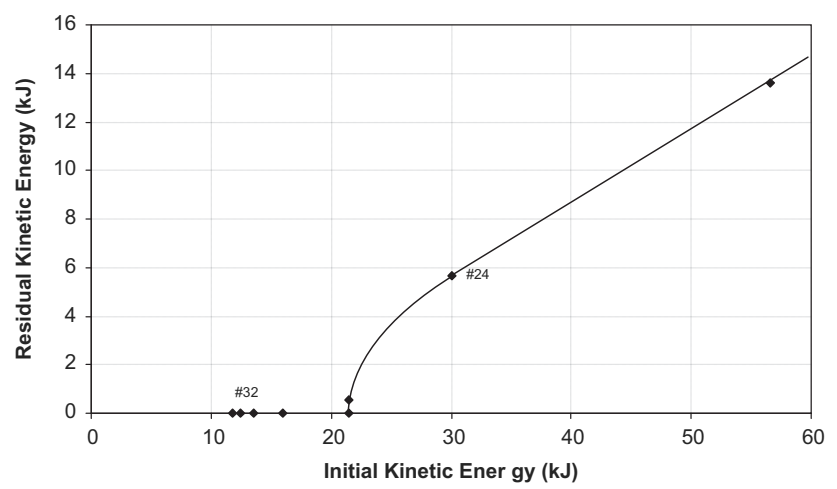

Figure 7. Ballistic limit curve for the experimental series with slabs $7 \mathrm{~cm}$ thick.

process. In order to get information on projectile deformation during soft impact and to validate the projectile material model and its data, a ballistic pendulum test is proposed. This test consists of launching a deformable projectile on a massive rigid body (weight of $153 \mathrm{~kg}$ ) hung to the ceiling with two steel cables (Figure 8). During the projectile crushing phase the load is transferred to the rigid mass that is accelerated. The measurement in the early time of the displacement, velocity, and acceleration give the value of the applied load.

In this experiment, projectile has been launched with a striking velocity of $89.2 \mathrm{~m} / \mathrm{s}$. Figure 9 shows the residual shape of the projectile at the end of test. We can observe a series of regular plies formed on the steel tube. The projectile residual lengths have been measured: $\mathrm{L}_{\mathrm{H}}=215 \mathrm{~mm}, \mathrm{I}_{\mathrm{H}}=0 \mathrm{~mm}, \mathrm{I}_{\mathrm{T}}=38 \mathrm{~mm}$.

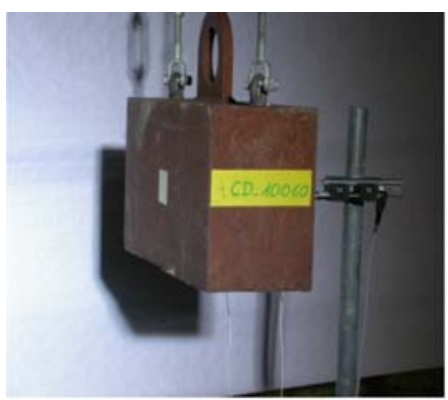

(a)

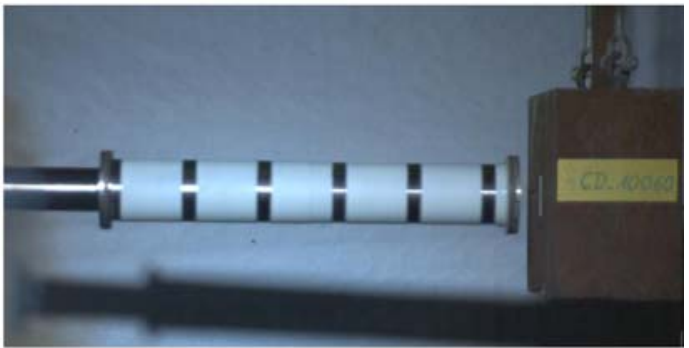

(b)

Figure 8. Ballistic pendulum device (a) and photo just before impact (b). 

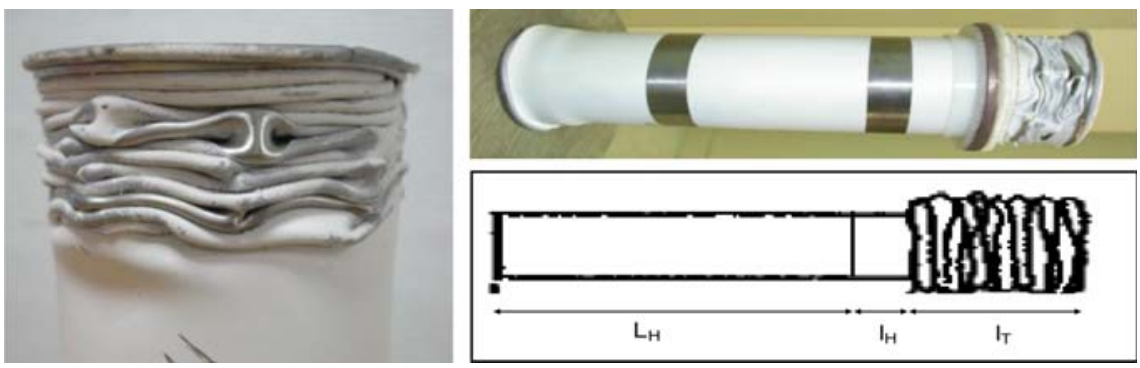

Figure 9. Projectile deformation after test $\left(\mathrm{V}_{0}=89.2 \mathrm{~m} / \mathrm{s}\right)$.

Using a displacement sensor located on the rear face of the steel block, the pendulum velocity can be obtained. During the first $5 \mathrm{~ms}$, the pendulum is set in motion then the velocity reaches a constant value of about $3.2 \mathrm{~m} / \mathrm{s}$.

\section{Numerical simulations}

These tests have been simulated using the finite element method and a specific concrete material model which is presented hereafter.

\subsection{Damage model for concrete: PRM Model}

A damage model has been developed at CEA-Gramat to simulate the behaviour of concrete under severe loading (Pontiroli, Rouquand, \& Mazars, 2010). This model, named "PRM model", includes two scalar damage variables that give respectively the loss of stiffness under tensile loading $D_{t}$ and the loss of stiffness under compressive loading $D_{c}$ (see Figure 10). Between these two loading states a transition zone is defined by $\left(\sigma_{f t}\right.$,

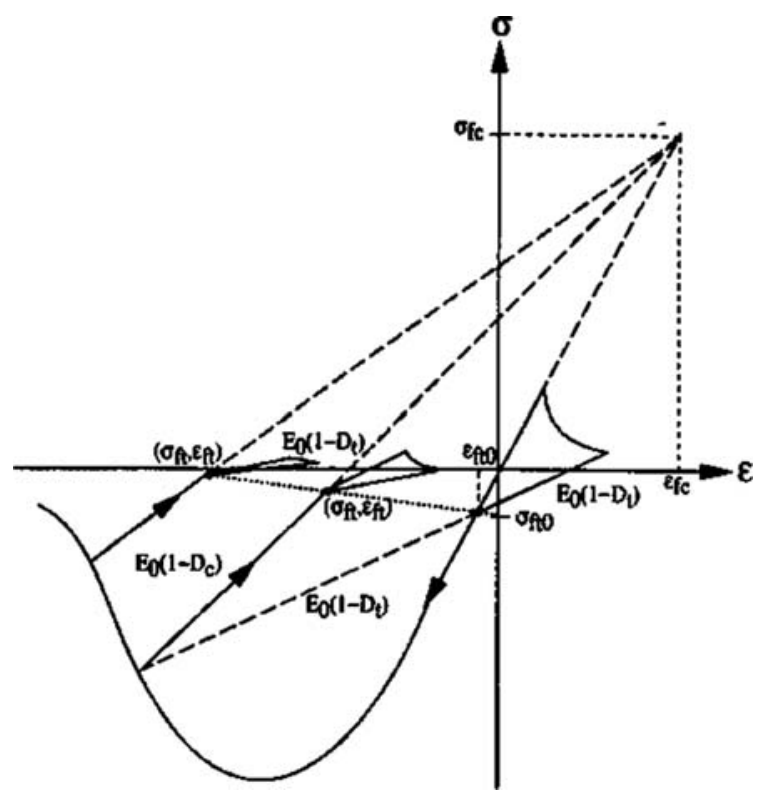

Figure 10. Stress strain curve for a tensile-compressive loading. 
$\varepsilon_{f t}$ ) where $\sigma_{f t}$ and $\varepsilon_{f t}$ are the crack closure stress and the crack closure strain respectively. The main equations of the PRM model for a uni-axial loading are:

For traction: $\left(\sigma-\sigma_{\mathrm{ft}}\right)=\mathrm{E}_{0}\left(1-D_{t}\right)\left(\varepsilon-\varepsilon_{f t}\right)$

For compression: $\left.\sigma-\sigma_{f t}\right)=\mathrm{E}_{0}\left(1-D_{c}\right)\left(\varepsilon-\varepsilon_{f t}\right)$

$\mathrm{E}_{0}$ is the initial Young's modulus and the damage evolution laws for $D_{t}$ and $D_{c}$ are controlled by an equivalent tensile strain (Mazars, 1984).

Strain rate effects are introduced to model the increase of the maximum tensile stress observed under moderate and high strain rate loading. Experimental data have been obtained on the R30A7 concrete using the Hopkinson bar facility at LEM3 laboratory (Metz, France) and using an impulsive electromagnetic pressure generator device (GEPI) at CEA-Gramat (see Figure 11).

A frictional stress is also added to simulate hysteresis loops during unloading and reloading paths (Figure 12). These frictional stresses introduce internal damping forces which are frequency independent but are related to damage parameters and then to tensile cracking phenomena. This effect can be significant for structural bending response and is essential to reproduce correctly residual displacement.

Under a high pressure regime in porous material like concrete, irreversible shear strain can be observed like compaction and shear yield. These phenomena can drive a significant part of the material response (Gabet, Malécot, Daudeville, 2008; Vu, Malécot, Daudeville, \& Buzaud, 2008). In order to take into account all these physical mechanisms, the plastic Krieg model has been coupled to the PRM damage model (Pontiroli et al., 2010).

But the plasticity part of the PRM model has not been activated to simulate the soft impact tests carried out at CEA-Gramat. In our experiments the damage drives the concrete response and confinement pressure does not seem to be sufficient to play a significant role in the concrete behaviour. Impact numerical simulations performed in this study have showed a maximum mean stress about 60-80 MPa in concrete.

The Hillerborg regularisation concept (Hillerborg, Modeer, \& Petersson, 1976) has been applied to limit mesh dependency during strain and damage localisation phenomena.

The PRM model is available as a user subroutine (VUMAT) in the ABAQUS explicit finite element code. It is compatible with almost all the finite element library (1D truss elements, beam elements, 2D plane strain and plane stress elements, 2D axisymmetric elements, 3D solid elements).

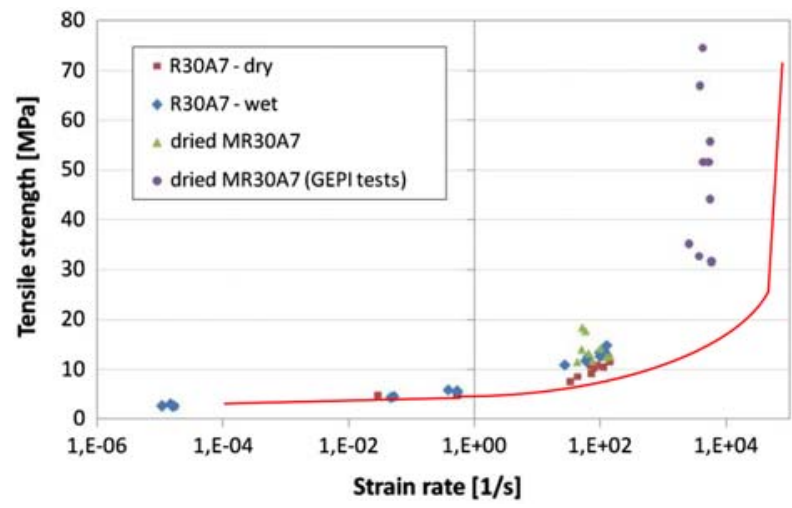

Figure 11. Experimental strain rate effects obtained on the R30A7 concrete (Erzar et al., 2009). 


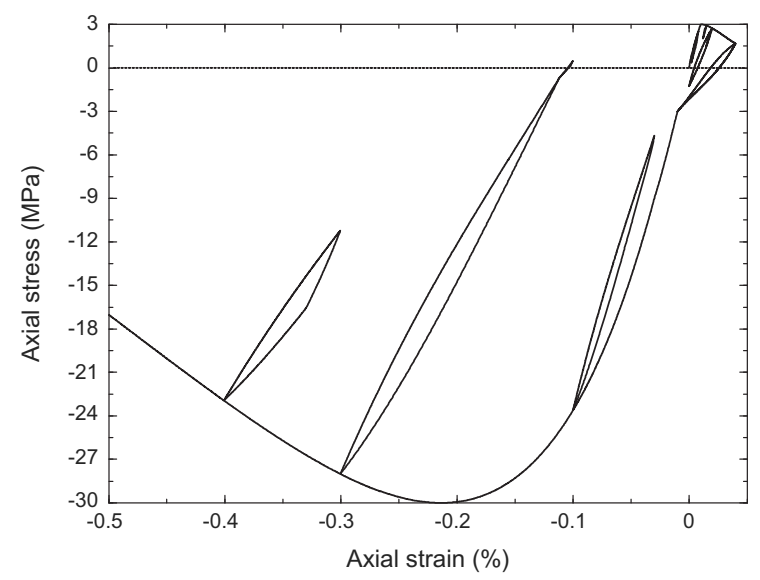

Figure 12. PRM damage model: cyclic loading including damping stresses.

\subsection{Plastic model for steel rebar}

The behaviour of the steel reinforcement is simulated using the Johnson Cook dynamic failure model (Johnson \& Cook, 1985). This model allows for strain rate effect on the material strength but also on the material ductility (see Figure 13). For failure under high strain rates, these two effects must be taken into account to correctly reproduce material response.

In the classical Johnson/Cook model, the plastic stress $\bar{\sigma}$ is related to the plastic strain, $\bar{\varepsilon}^{p l}$ to the plastic strain rate $\dot{\bar{\varepsilon}}^{p l}$ and to the damage variable $D$ via the following expression:

$$
\bar{\sigma}=(1-D)\left[A+B\left(\bar{\varepsilon}^{p l}\right)^{n}\right]\left[1+C \ln \left(\frac{\dot{\bar{\varepsilon}}^{p l}}{\dot{\varepsilon}_{0}}\right)\right]
$$

where $\dot{\varepsilon}_{0}$ is a reference strain rate. $A, B, n$ and $C$ are material parameters.

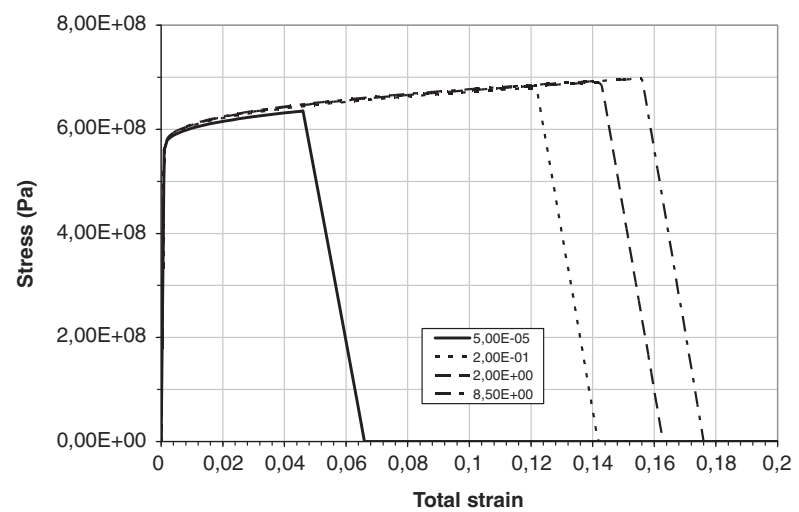

Figure 13. Example of a stress strain curve (Johnson/Cook dynamic failure model), for different strain rates. 
The damage $D$ is related to the plastic strain as follows:

$$
D=\min \left[\frac{L_{e} \max \left(\left(\sum_{i} \Delta \bar{\varepsilon}_{i}^{p l}-\bar{\varepsilon}^{p l 0}\right), 0\right)}{L_{0} \bar{\varepsilon}_{f}^{p l}}, 1\right]
$$

$\bar{\varepsilon}^{p l 0}$ is the plastic threshold. The damage variable $D$ is incremented when the cumulated plastic strain $\sum_{i} \Delta \bar{\varepsilon}_{i}^{p l}$ becomes greater than the plastic threshold $\bar{\varepsilon}^{p l 0}$

The plastic threshold $\bar{\varepsilon}^{p l 0}$ is given by:

$$
\bar{\varepsilon}^{p l 0}=d_{1}\left[1+d_{2} \ln \left(\frac{\dot{\bar{\varepsilon}}^{p l}}{\dot{\varepsilon}_{0}}\right)\right]
$$

where $d_{1}$ and $d_{2}$ are material parameters, $L_{e}$ is the element characteristic length and $L_{0} \bar{\varepsilon}_{f}^{p l}$ is the failure displacement.

Figure 13 shows stress strain curve obtained with the Johnson/Cook dynamic failure model for S235 steel material used for rebar. We have the following material parameters: $A=480 \mathrm{MPa}, B=153 \mathrm{MPa}, n=0.36, C=0.0141, d_{1}=0.045, d_{2}=0.203, L_{0}=$ 0.2 .

In this figure, the curves correspond to different constant strain rates given in the legend.

\subsection{Numerical results}

Numerical simulations of soft impact tests are not easy because there are strong interactions between the target behaviour and the projectile crash process. Correct predictions require a proper modelling of both the target and the missile response. In order to evaluate the capabilities of the explicit finite element code Abaqus including the PRM model, 3D numerical simulations of CEA-Gramat impact tests have been undertaken. The objective is to determine the capabilities and the limits of such simulations.

\subsubsection{Ballistic pendulum simulation}

First, to validate the deformable projectile model, the ballistic pendulum test has been simulated. The projectile is composed of a thin steel tube which is efficiently modelled using 3D shell elements (1568 elements). Eight nodes solid elements have been used for the massive steel block. 1D truss elements are used for the steel cables (Figure 14 (a)).

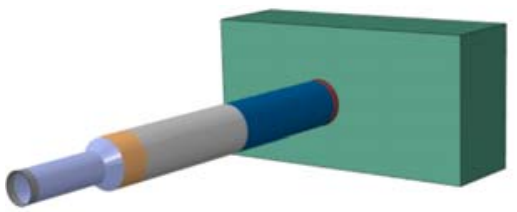

(a)

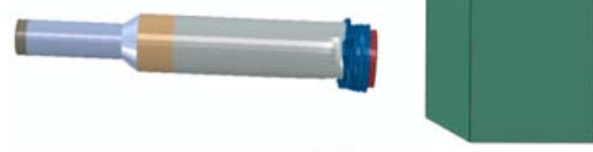

(b)

Figure 14. Ballistic pendulum simulation. 
The classical Johnson/Cook model is used for projectile steel with the following material characteristics: $A=480 \mathrm{MPa}, B=300 \mathrm{MPa}, C=0.12, n=0.36$. As experiments have not showed failure on the projectile, we have not used the dynamic failure option in the Johnson/Cook model.

The residual projectile shape shown on Figure 14(b) gives a reasonably good approximation of the experimental result presented on Figure 9. Projectile residual lengths are in good agreement $\left(I_{T}=38 \mathrm{~mm}\right)$ but the total number of plies is underestimated by the simulation (seven plies obtained numerically and 13 experimentally). The mesh of the projectile seems to be too coarse to reproduce correctly the plies formation during the crush.

On Figure 15, the projectile velocity (calculated by integration of the accelerometer signal) and the massive steel block velocity (calculated by derivation of the displacement signal) obtained during the experiment, are compared to the numerical results. The numerical simulation is able to reproduce the missile deceleration and the rebound at the end of the impact process. A good agreement is also obtained for the pendulum motion and a constant velocity close to $3.2 \mathrm{~m} / \mathrm{s}$ can be found by the simulation.

Although a coarse mesh of the projectile is used, which is unable to reproduce accurately the local buckling, the numerical approach can catch the global response of the projectile in terms of velocity and deceleration (and so in terms of total forces applied to the structure). No simulation with refine mesh for the projectile has been carried out:
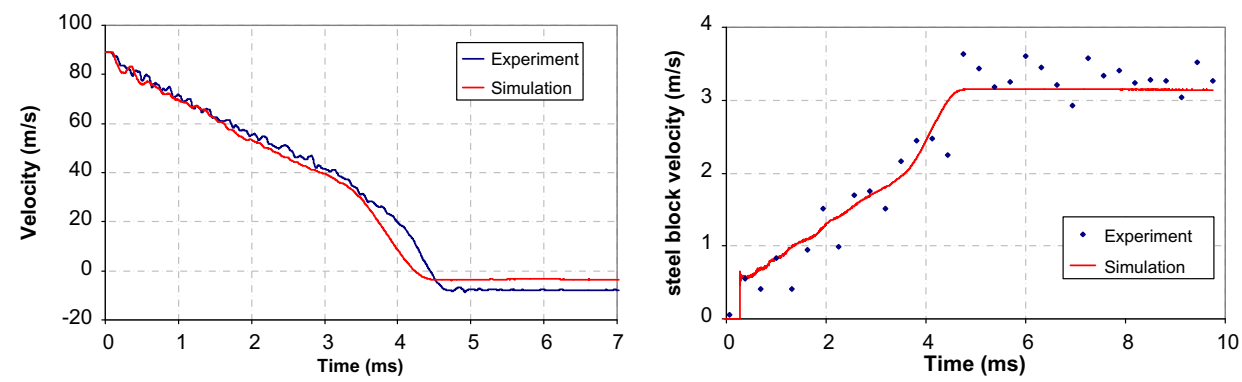

Figure 15. Evolutions of the projectile and pendulum velocities $\left(\mathrm{V}_{0}=89.2 \mathrm{~m} / \mathrm{s}\right)$.

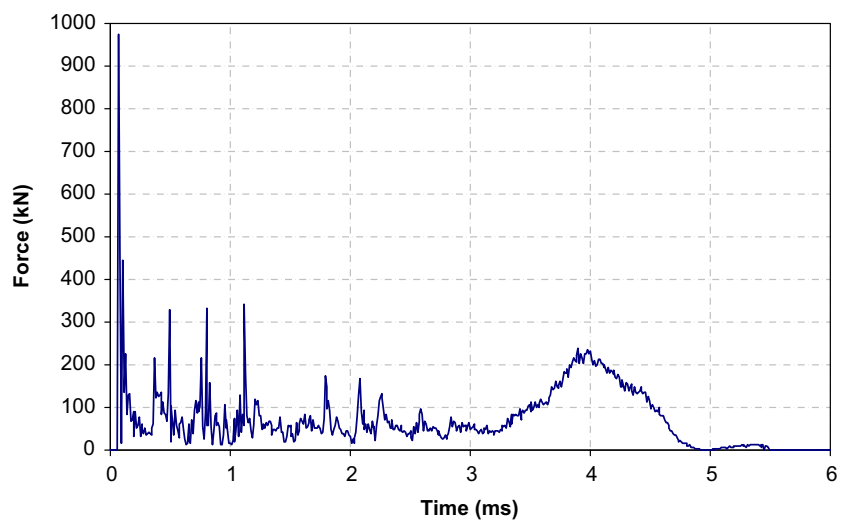

Figure 16. Evolution of the computed projectile impact force. 
the aim objective of the ballistic pendulum simulation was to reproduce the projectile global response and in this way validate the load applied on the structure.

Figure 16 shows the evolution of the computed force versus time. This force is exerted by the projectile on the steel block during the impact. The force oscillations are related to the plies formation. A series of plies is developed during the projectile crushing process. The maximum of the force, about $1000 \mathrm{kN}$, is reached when the previous ply is completely done and when the buckling load initiating the formation of the next ply is obtained. During the ply formation, the load decreases a lot. Thereafter the ply formation is ended when contact conditions are established on the last ply in formation. Finally the load continues to increase until the next ply formation starts. At $4 \mathrm{~ms}$, the increase of force, about $200 \mathrm{kN}$, corresponds to the crash of the second part of the projectile with a thickness of $2 \mathrm{~mm}$. We can correlate this large deceleration to the loss of velocity observed on Figure 15 at $4 \mathrm{~ms}$.

\subsubsection{Simulation of the perforation test}

A 3D finite element model with solid brick elements has been used for the target (60,000 eight nodes solid elements). The reinforcement is explicitly modelled using two nodes beam elements with a circular cross section (3342 elements). These reinforcement elements are embedded in the concrete finite element mesh. Two symmetry planes are used and only a quarter of the plate and the projectile is modelled. Concrete nodes are not coincident with the reinforcement nodes but a displacement constraint is applied on these nodes in order to simulate a perfect link between steel and concrete. The projectile mesh and the material model are the same as those defined in the ballistic pendulum simulation.

Figure 17 shows the projectile/target interaction at 2.5 and $10 \mathrm{~ms}$ during the test no. 1. We can observe scabbing phenomena, the formation of a concrete plugging cone and the failure of the reinforcement during the projectile penetration phase. Failure mechanisms seem to reproduce very well the experimental observations. For erosion

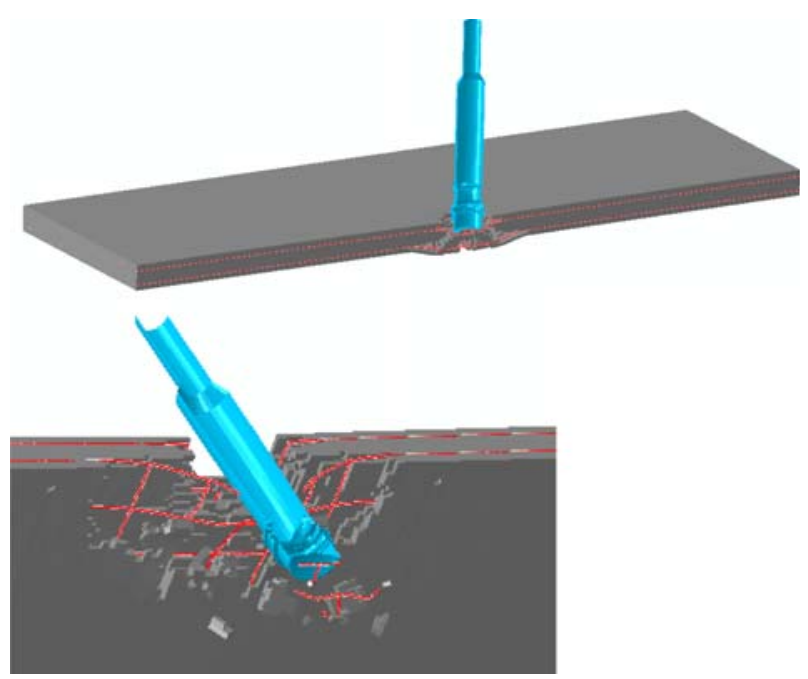

Figure 17. Numerical simulation results obtained at $2.5 \mathrm{~ms}$ and at $10 \mathrm{~ms}$ (test no. $1, \mathrm{~V}_{0}=107.5$ $\mathrm{m} / \mathrm{s})$. 

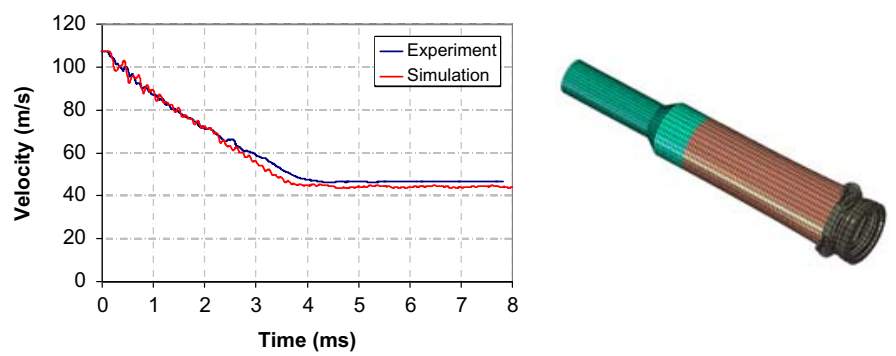

Figure 18. Evolution of the projectile velocity and residual projectile shape (test no. $1, \mathrm{~V}_{0}=$ $107.5 \mathrm{~m} / \mathrm{s}$ ).

technique, we used in PRM model an erosion criterion based on principal tensile strains developed during damage process (this criterion takes into account the strain rate effects and the Hillerborg method).

On Figure 18, the projectile velocity obtained during the test (calculated by integration of the accelerometer signal) is compared to the numerical velocity. The simulated velocity profile matches accurately the experimental data, especially the residual velocity at the end of the perforation process. On this figure, we can also observe the residual projectile shape that can be compared to the experimental residual shape shown in Figure 3 (the first cylinder part with a thin wall thickness of $1 \mathrm{~mm}$ is completely buckled).

To verify the independence of numerical solutions to the mesh size, we have increased the element's number by a factor of two in all directions on the concrete slab (480,000 eight nodes solid elements). Figure 19 compares projectile velocity evolution during impact obtained with a coarse mesh (a) and a fine mesh (b). A good agreement is observed despite the large difference between the mesh sizes.

Figure 20 presents projectile/target interaction at $5 \mathrm{~ms}$ after impact. Same local deformation on projectile and slab can be observed with both mesh sizes. Cratering and scabbing seem to develop similarly on concrete structure. CPU time is about 20 minutes for coarse mesh and $3 \mathrm{~h} 21 \mathrm{~min}$ for fine mesh (simulations performed on 8 SGI processors).

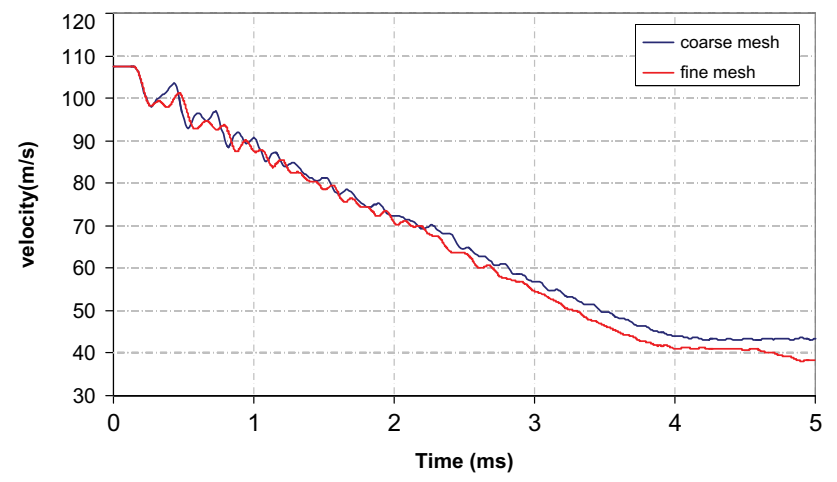

Figure 19. Evolution of the projectile velocity for two mesh sizes. 


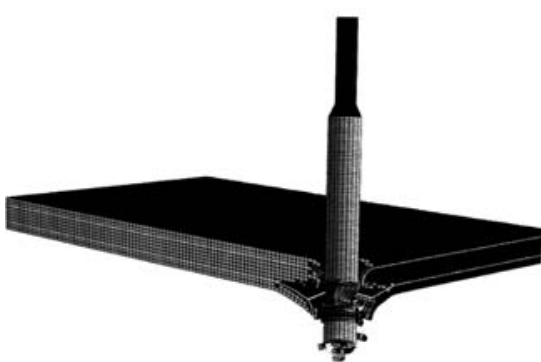

(a)

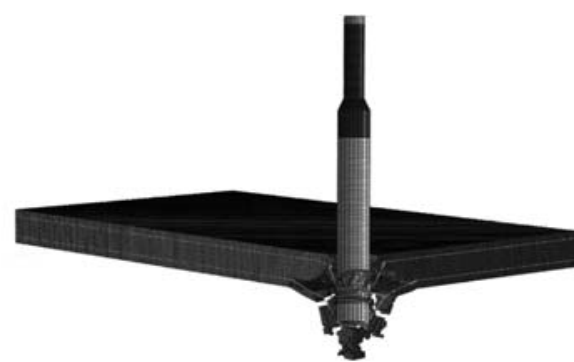

(b)

Figure 20. Numerical result for coarse mesh (a) and fine mesh (b) at $5 \mathrm{~ms}$ (test no. 1, $\mathrm{V}_{0}=$ $107.5 \mathrm{~m} / \mathrm{s})$.

\subsubsection{Simulation of the non-perforating test}

Material data used in the previous simulations is also used here. In Figure 21 we compare the numerical and the measured projectile velocities obtained in test no. 2 . The numerical simulation is able to reproduce the missile deceleration and the rebound at the end of the impact process. In this figure we also observe the projectile shape at the end of the numerical simulation (to be compared with Figure 5). The first cylinder part with a thin wall thickness of $1 \mathrm{~mm}$ is buckled in both figures over a length of about $150 \mathrm{~mm}$.

In Figure 22 is shown the computed damage pattern shape observed on the front and the rear faces and through the thickness of the target at the end of the numerical simulation (at $200 \mathrm{~ms}$ ). The contours plotted on the reinforced concrete target give the maximum values reached by the principal tensile strains. The blue contour corresponds to yielded rebar. This means that residual open cracks are visible on the blue part but not on the grey part. Numerical results show that the reinforcement does not fail (reinforcement maximum tensile strains remain below 5\% everywhere in the reinforced concrete plate) but formation of a plugging cone is initiated on the rear face of the reinforced concrete plate (as in the experiment - see Figure 6).

In Figure 23 is shown the displacement histories of the two points DV2 and DV4 located on the rear face of the reinforced concrete plate. A good agreement is observed between experiment and simulation concerning the maximum displacements but
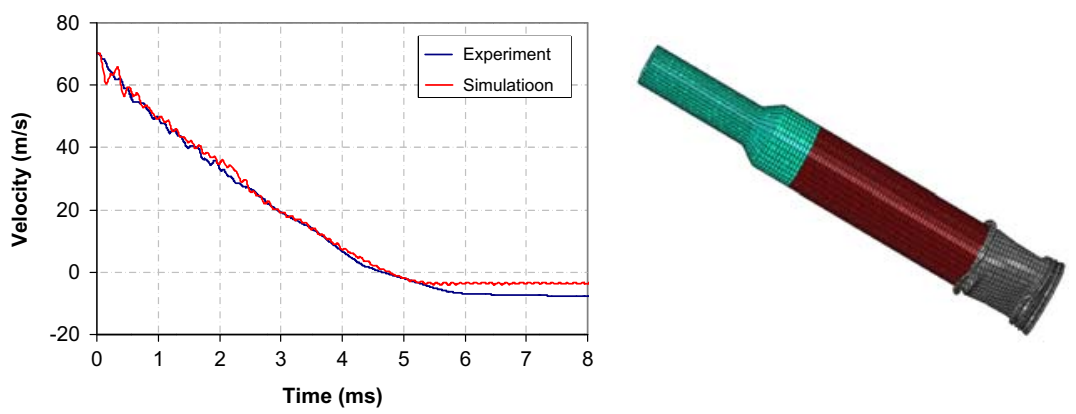

Figure 21. Evolution of the projectile velocity and projectile shape (test no. $2, \mathrm{~V}_{0}=70.2 \mathrm{~m} / \mathrm{s}$ ). 


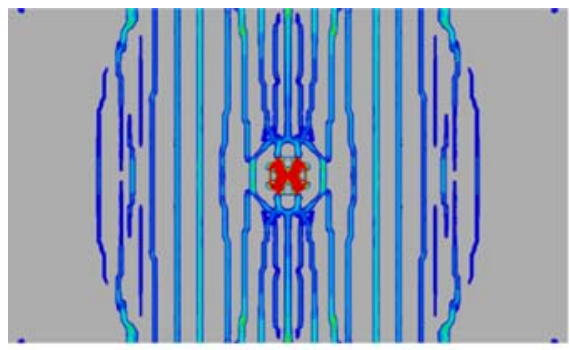

Front face

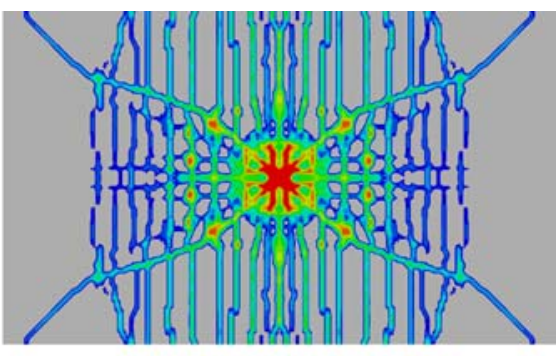

Rear face

Figure 22. View of the maximum principal tensile strains reached on the reinforced concrete target during the impact (test no. $2, \mathrm{~V}_{0}=70.2 \mathrm{~m} / \mathrm{s}$ ).
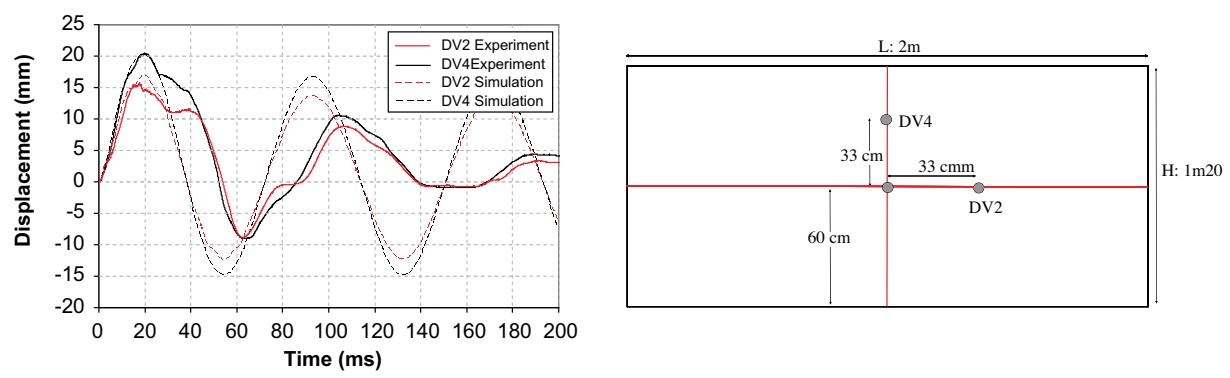

Figure 23. Measured and computed displacements at point DV2 and DV4 (test no. 2, $\mathrm{V}_{0}=70.2$ $\mathrm{m} / \mathrm{s})$.

damping is undervalued in the computation. Perhaps frictional forces between the reinforced concrete slab and the supports explain such phenomena.

\section{Conclusions}

An experimental and modelling approach of soft projectile impact on thin slabs presented in this paper demonstrates the efficiency of the proposed explicit finite element procedure to capture the real behaviour of the reinforced concrete structure and projectile.

New soft projectile impact experiments completed by material characterisations in static and dynamic loadings provide a relevant experimental database to carry out numerical simulations and validate the modelling approach. The ballistic pendulum test validates the projectile model before to simulate the complex projectile/target interaction.

The numerical results show the capabilities of the PRM model for concrete and the Johnson/Cook dynamic failure model for a steel rebar to reproduce accurately the bending response of the reinforced concrete slab and the concrete failure mode due to the projectile impact (displacements - damaged areas, crack pattern, plugging and scabbing damage modes of the reinforced concrete slab - velocity and residual shape of the projectile). 
A damage model with irreversible strains and strain rate effects in tension seems relevant to correctly catch the different mechanisms which occur on concrete. Due to the damage localisation process, this model has to be coupled to a regularisation method to limit mesh size effects on structural response.

Using Johnson/Cook dynamic failure model for steel reinforcement allows one to reproduce strain rate effects on material strength but especially on ductility.

This modelling approach can advantageously help to predict the vulnerability of reinforced concrete structures to impact problems.

\section{Acknowledgements}

This concrete programme research has been performed with the financial support of the French Ministry of Defence (DGA). The French Agency (ANR PGCU 2007) and 3SR Laboratory at Grenoble are also gratefully acknowledged.

\section{References}

Baroth, J., Daudeville, L., \& Malécot, Y., (2012). About empirical models predicting the missile perforation of concrete barriers. European Journal of Environmental and Civil Engineering, (to appear).

Erzar, B., Forquin, P., Buzaud, E., \& Pontiroli, C. (2009). Tensile strength of mortar over a wide range of strain rate. Proceedings DYMAT2009, 603-609, DOI: 10.1051/dymat/2009086. Bruxelles: Publisher.

Gabet, T., Malécot, Y., \& Daudeville, L. (2008). Triaxial behavior of concrete under high stresses: Influence of the loading path on compaction and limit states. Cement and Concrete Research, $38(3), 403-412$.

Hillerborg, A., Modeer, M., \& Petersson, P.E. (1976). Analysis of crack formation and growth in concrete beams of fracture mechanics and finite elements. Cement and Concrete Research, 6, $773-782$.

Johnson, G.R., \& Cook, W.H. (1985). Fracture characteristics of three metals subjected to various strains, strain rates, Temperatures and pressures. Engineering Fracture Mechanics, 21(1), 3148.

Jonas, W., Rüdiger, E., Gries, M., Riech, H., \& Rûtzel, H. (1982). Kinetische Grenztragfähigkeit von Stahlbetonplatten, RS 165, Schlussbericht (Rapport final, IV). Technischer Bericht, Hochtief $A G$.

Mazars, J. (1984). Application de la mécanique de l'endommagement au comportement nonlinéaire et à la rupture du béton de structure. France: Thèse d'état de l'Université Paris VI, France.

Pontiroli, C., Rouquand, A., \& Mazars, J. (2010). Predicting concrete behaviour from quasi-static loading to hypervelocity impact. An overview of the PRM Model. European Journal of Environmental and Civil Engineering, 14(6-7), 703-727. doi: 10.3166/ejece.14.703-727.

Riech, H., \& Rüdiger, E. (1984). Versuchsergebnisse des Meppener Versuche II/11 bis II/2 (Results on MEPPEN tests II/11 to II/22). Technischer Bericht 1500408 (RS 467).

Rouquand, A. (2010). IRIS 2010 International Benchmark. Impact of soft projectiles on a reinforced concrete plate: Presentation of the CEA-Gramat results, Technical Report, Commissariat à l'Energie Atomique, Gramat, France.

Saarenheimo, A., Tuomala, M., Hakola, I., Hyvärinen, J., Aalto, A., \& Myllymäki, J. (2007). Impacts of deformable missiles on reinforced concrete walls. CONSEC'07, 1381-1388, http:// URN.fi/URN:NBN:fi:tty-201104155211. Tours, France. Publisher.

Vu, X.H., Malecot, Y., Daudeville, L., \& Buzaud, E. (2008). Experimental analysis of concrete behavior under high confinement: Effect of the saturation ratio. International Journal of Solids and Structures, 46(5): 1105-1120. doi: 10.1016/j.ijsolstr.2008.10.015. 